\title{
Schwarzkopf in 'Nam
}

\author{
By David Sutton
}

Fall 1998 Issue of KINEMA

During the summer of 1993, CBS News aired an hour-long television special program entitled Schwarzkopf in Vietnam: A Soldier Returns. This program, hereafter referred to as SVN:ASR, featured a return trip to Southeast Asia by retired US Army General H. Norman Schwarzkopf and CBS News personality Dan Rather, both of whom served in different capacities in Southeast Asia during the war years. Their current trip to Vietnam was the first time either person had been back to Indochina since the end of the war in April 1975.

First and foremost, we must recognize that this particular program is a commodity. SVN:ASR was broadcast on network television, which like any other commercial enterprise exists to make a profit. Viewing this artifact at face value, the program appeared to be strictly informative -- a televised lesson in American military history given by a well-known military figure. One could reasonably surmise that the network executives' primary purpose for producing and airing this particular program was to attract an audience in order to make money. What I found most intriguing about this television program was the format. In addition to the history lesson, the program's audience witnesses the outward manifestations of an inner rebirth for Schwarzkopf. He is portrayed as undergoing what Carl Gustav Jung labeled a renovatio, an archetypal rebirth. Schwarzkopf exchanges a wounded persona, one that is wracked with psychological scars and guilt brought on by his Vietnam War experience, for a restored persona which acknowledges the past but is no long possessed by it.

In The Philosophy of Literary Form, Kenneth Burke presents a critical methodology which contains a distinctly mathematical twist. Burke states that analyzing any text "requires us to get our equations inductively, by tracing down the interrelationships as revealed by the objective structure of the [text] itself" (70). In addition to discerning the opposing principles, or the "what is vs. what" (69), a critic should also look for "the development from what through what to what" (71). Burke suggests that critics use several mathematical symbols in their exploration of a particular work, e.g., the arrow, the equal sign, or an arrow with a diagonal slash through it (75-77). What follows is an attempt to apply this quasi-mathematical method to a text.

Applying Burke's method as described above to SVN:ASR, five equations emerged. Each is diagramed and explained below.

Equation 1: Contemporary agent-scene -- Reconstructed agent-scene -- Contemporary agentscene

During SVN:ASR, the audience travels with Schwarzkopf and Rather to various locations throughout contemporary Vietnam, beginning in Ho Chi Minh City (formerly known as Saigon) and ending in Hanoi. After arriving at a contemporary site, Rather reconstructs an historical scene, using newsreel footage, still photographs, interviews with former members of Schwarzkopf's command, and his own wartime memories. He then prompts Schwarzkopf to add some details for further clarification. The final reconstructed scene of wartime Vietnam has the appearance of an impressionist painting, i.e., the exact re-creation of objective reality is not the primary goal but instead the evocation of subjective reactions. Following the same technique, they reconstruct a younger Schwarzkopf, who then acts within the reconstructed scenes of the Vietnam War. From the opening moments and throughout much of this television program, Schwarzkopf dominates the contemporary and reconstructed scenes. His actions, emotions, memories, opinions, and thoughts are the focus of a large portion of the broadcast.

David A. Ling discussed this relationship of agent to scene in a pentadic analysis of Senator Edward Kennedy's July 25, 1969 address to the people of Massachusetts. In order to reduce his culpability for the drowning of Mary Jo Kopechne, Kennedy portrayed himself as a victim of the scene. As Ling notes, this strategy worked against Senator Kennedy's presidential aspirations. Americans expect their president to be a person who can act decisively and think clearly regardless of changing events. 
In direct contrast, the viewers of SVN:ASR see that Schwarzkopf is no victim of circumstances. The conditions during his two combat tours in Southeast Asia were far from ideal, but nevertheless he overcame adversity and did his job. Even under the most horrifying conditions of war, the reconstructed Schwarzkopf demonstrates his ability to maintain his clarity of thought. For example, Rather describes the scene of 28 May 1970, in which the reconstructed Schwarzkopf arrives by helicopter at an area known as the Batagnan Peninsula. This region was particularly dangerous, Rather tells us, because the Viet Cong had planted an extraordinary number of land mines throughout the area. Recorded interviews with former members of Schwarzkopf's battalion paint a truly hellish scene: no one could move without detonating a mine, and the screams of the wounded fill the air. Despite his own fears, the reconstructed Schwarzkopf renders first aid to a badly wounded soldier. Even after one of his officers detonates a land mine a few feet from him, Schwarzkopf maintains his self-control and loads several other wounded soldiers on board a Medivac helicopter.

Because of its emphasis on the agent in both the contemporary and reconstructed scenes, the dominant philosophy espoused in SVN:ASR is idealism. Burke writes in A Grammar of Motives that idealistic philosophies "think in terms of the 'ego,' the 'self,' the 'super-ego,' 'consciousness,' 'will,' the 'generalized I,' the 'subjective,' 'mind,' spirit,' the 'oversoul,' and any such 'super-persons' as church, race, nation, etc." (171). As Charles U. Larson notes, people who stress the agent as the key element in their discourse believe that "strong individuals determine the outcome of events" (136). In SVN:ASR, we the audience see the contemporary and reconstructed Schwarzkopf as authoritative and self-assured, an individual who manifests a total command of his mental, physical, and spiritual faculties.

In his autobiography It Doesn't Take A Hero, Schwarzkopf writes about the influence his years as a West Point cadet had on shaping his inner life:

Somehow, during the four years I spent in that idealized military world, a new system of values came alive in my mind. When I began as a plebe, 'Duty, Honor, Country' was just a motto I'd heard from Pop. I loved my country, of course, and I knew how to tell right from wrong, but my conscience was still largely unformed. By the time I left, those values had become my fixed stars (72).

In 1966, after completing his first combat tour in Vietnam, Schwarzkopf returned to his beloved West Point as a mechanical engineering instructor. He writes that teaching gave him "a new sense of mission." Part of that mission for him was molding young "goats" into exceptional military officers. In Schwarzkopf's classroom, a discussion of virtues was often co-mingled with lessons about "why wheels roll down hills." He writes, "Often, I'd put aside the textbook, sit on the edge of the desk, and talk about what it meant to be an officer, about values and morality and honor" (137).

The inner strength displayed by Schwarzkopf in SVN:ASR allows him to do something highly unusual for a military officer, i.e., openly express his emotions. In response to Rather's questioning, Schwarzkopf freely recounts his emotional memories of his Vietnam War experiences, which is a key element in the next two equations.

\section{Equation 2: Presence in Scene + Admission of Emotions $=$ Permission to Criticize}

The free expression of emotion by Schwarzkopf is perhaps the most striking feature of SVN:ASR. We see and hear this famous Vietnam veteran, a soldier who won medals for valor on the battlefield, unashamedly portray a wide-range of feelings, e.g. anger, apprehension, compassion, disappointment, depression, determination, doubt, elation, fear, grief, guilt, pride, relief, and sadness.

In SVN:ASR, Schwarzkopf's presence in the reconstructed scenes of wartime Vietnam plus his free expression of emotion equals permission to criticize US military strategy in Southeast Asia. Having served as a military adviser to the South Vietnamese airborne in 1966, the Schwarzkopf labels the escalation and Americanization of the war in the late-1960s "a terrible mistake." After recounting his harrowing adventure in the Batagnan Peninsula minefields, Schwarzkopf proclaims, "War is insanity." Later in the program, Schwarzkopf agrees with Rather that the US military's war of attrition in Vietnam was "absolutely a bankrupt strategy."

There are several points in SVN:ASR when Rather and Schwarzkopf use this second equation disingenuously. In the most egregious example, Rather takes the audience back to the fall of Saigon in April 1975. He reconstructs a scene of a beleaguered city in the final days of a massive siege. The viewers learn that in 
1975, during the final days of the Vietnam War, Schwarzkopf was commanding an army brigade in Alaska. In response to Rather's questioning, Schwarzkopf reveals his emotional state at the time, satisfying one part of this equation: "I cried like a baby, and I got out a bottle of scotch and I got drunk."

The equation dictates that in order for the contemporary Schwarzkopf to criticize, he must not only admit to an emotion but also be present in the reconstructed scene. This geographical and temporal difficulty is overcome as Rather and Schwarzkopf take a walk across the rooftop of the former US embassy in Ho Chi Minh City. This location was the Vietnam War's concluding scene, as American helicopters shuttled desperate Vietnamese to US warships stationed offshore. Overlooking the contemporary city, Rather turns to Schwarzkopf and asks, "What are you thinking about up here?" As the contemporary Schwarzkopf speaks in a voice over, the television audience sees more newsreel footage of smoke rising behind distant buildings, tanks driving through streets, desperate Vietnamese refugees passing their children over a fence to waiting Americans. Schwarzkopf "recalls" the reconstructed battle scene in detail, as if drawing from a deep well of memories. In fact, no such reservoir of memories exists. Yet, his artificial insertion into the chaotic scene of the Vietnam War's last days allows the contemporary Schwarzkopf to offer the television audience a final, definitive criticism of the Vietnam War:

I was convinced that we were abandoning these people. And I - the thought that just kept going through my mind is - is 50,000 American lives. How many legs and arms were blown off, how many families were blown apart figuratively by the war and for what? And I've got to tell you what, at that point the answer kept coming back: For nothing.

Kathleen H. Jamieson writes that television is an "intimate mass medium" in which a rhetor is virtually compelled to use an emotional or feminine speaking style. The feminine style requires a speaker to unveil his/her feelings and to reveal some part of the private self. Most male politicians, Jamieson argues, have found this requirement to be a significant barrier in their use of television as a campaigning tool (81-82). No such barriers exist for Rather and Schwarzkopf. Schwarzkopf can criticize American military strategy because he is coming from a feminine vantage point. No one can tell him how he felt; his feelings are his own. The largely emotional quality of SVN:ASR serves as a face-saving device for Schwarzkopf. If he had employed a more masculine/ analytical approach, i.e., naming specific policy makers and pointing out the individual weaknesses of their decisions, he would have been vulnerable to a counterattack with the traditional arsenal of argument -- claims, data, and warrants. By using an feminine/ emotional speaking style, Schwarzkopf is free to criticize without opening himself up to accusations of disloyalty.

Equation 3: Presence in Scene + Admission of Emotions $=$ Permission to Answer Lingering Questions

At the Vietnamese national park at $\mathrm{Cu}$ Chi, Rather and Schwarzkopf examine part of the network of claustrophobic tunnels once used by Viet Cong guerrillas during the war years. Schwarzkopf never served near $\mathrm{Cu} \mathrm{Chi}$, so Rather relates his own wartime experience in this region to the audience. As discussed in the previous section, Rather then helps to artificially insert Schwarzkopf into a reconstructed combat scene. Rather asks Schwarzkopf about fighting "an army of moles." Schwarzkopf remembers walking down jungle trails and listening to mortar shells fall nearby. He admits that the experience was "unnerving." After his presence is established in the reconstructed scene and he admits to having an emotion, the scene shifts to a picnic table where Schwarzkopf and Rather address four lingering questions from the Vietnam War: (1) What are the lessons of Vietnam? (2) Did the press lose the Vietnam War? (3) Should the US restore full diplomatic relations with Vietnam?, and (4) Are there any living American POW/ MIAs left in Vietnam?

Questions (1) and (2) carry minimum risk for Schwarzkopf; he can offer his opinions because they relate directly to his combat experience. Following the strategy explained in the above equation, he again approaches his Vietnam experience from an emotional perspective. By staying largely in the emotional arena, Schwarzkopf is free to answer questions (1) and (2) without questioning the credibility of his fellow West Point graduates and his superiors. Questions (3) and (4) carry substantial risk because they relate to current foreign policy concerns, an area that could be judged by others to be outside of the realm of Schwarzkopf's expertise.

Rather and Schwarzkopf address questions (3) and (4) after they arrive in contemporary Hanoi. In this portion of the program, Rather diverts from a strict application of the second and third equations. As before, 
he reconstructs a scene of wartime Hanoi; however, he does not reconstruct a younger Schwarzkopf to enter and act within the scene. Rather asks the contemporary Schwarzkopf to express his feelings about walking through the capitol city of his former enemies. Schwarzkopf admits that he was nervous at first, expecting "a bogeyman behind every tree or bush," but after a short time he realizes that Hanoi is "just another city." Dan Rather then becomes the primary agent who answers the two remaining, and most controversial, questions. Schwarzkopf accompanies Rather through the streets of Hanoi, but he does not speak, he offers no opinion on either issue.

Jamieson recounts the many forms of physical and psychological abuse used throughout history to silence women. "By falling silent or speaking submissively," Jamieson writes, "women purchased protection"(70). By falling silent, Schwarzkopf "purchased" protection from having to answer questions (3) and (4). The issue of living Vietnam War American POW/MIAs and the restoration of diplomatic relations with Vietnam have long been emotionally intertwined in the minds of many Americans (Sutton). Taking a position on these two questions would involve a high degree of risk for Schwarzkopf. For him to adopt an "effeminate" style by remaining silent, was the safest course of action.

\section{Equation 4: Victory in the Persian Gulf War = Forgiveness for Vietnam}

In considering the form of literary works as an integral part of their analysis, Burke writes in The Philosophy of Literary Form that "if you look for a [person's] burden, you will find the principle that reveals the structure of [her/his] unburdening . . ." (92). What is apparent to the viewers of SVN:ASR is the sheer weight of Schwarzkopf's emotional burden caused by his participation in the Vietnam War. By the early 1970s, Schwarzkopf tells Rather, morale among US combat forces was at an all time low: "People in our own country were blaming us, calling us baby-killers. Somehow the war had become our fault rather than someone else's fault, and I think that we were - we somehow felt guilty that we hadn't won." The intensity of Schwarzkopf's emotional burden comes through also from the printed page. In his autobiography, Schwarzkopf remembers the emotional pain he felt in the early 1970's caused by the American public's withdrawal of moral support for the armed forces. The effect upon him and other members of the US military, Schwarzkopf writes, was devastating: "We soldiers, sailors, airmen, and Marines were literally the sons and daughters of America, and to lose public support was akin to being rejected by our own parents" (181).

In viewing SVN:ASR, one sees the structure of Schwarzkopf's solution. He has placed himself in the position of a child who is estranged from his parents, and his wish is to mend this relationship. Children try to mend things with their parents by doing something good. Schwarzkopf reveals that something good was winning the Persian Gulf War. Victory in the Gulf, in Schwarzkopf's estimation, washed away the stain of the Vietnam War from the American military.

One could argue against Schwarzkopf's assessment of the Gulf War by taking what Burke refers calls a "scientistic" approach (Language 9-13). A strictly quantitative comparison of the Vietnam War and the Persian Gulf War would reveal two distinct conflicts, widely disparate on factors such as terrain, time, and number of casualties. Schwarzkopf's rhetoric, as it appears in SVN:ASR and his autobiography, maintains a "dramatistic" approach. Olson writes that the dramatistic perspective "encourages the adoption of an idealistic axiology" and reminds us again of Burke's association of idealism with the agent (132).

In his autobiography, Schwarzkopf describes the Vietnam War's debilitating influence on the US Army's officer corps, mainly it had become a system replete with agents who had forsaken their ideals. By 1970, Schwarzkopf writes, "the system had been subverted to condone selfish behavior and tolerate incompetent commanders who sacrificed their subordinates and distorted facts to get ahead" (178). Ineptitude, corruption, and careerism reached all the way up to the highest levels of command. A process began at the end of the Vietnam War to remove the ineffectual and unscrupulous officers/ agents who had weakened the military. By the 1990s the officer corps was cleansed and revitalized. From Schwarzkopf's "dramatistic" perspective, the Persian Gulf War was fought by a refurbished US military, one that had been cleansed of its counterproductive agents. The final act of purification was the defeat of the Iraqi army. For Schwarzkopf and others, Operation Desert Storm was the antidote for the Vietnam Syndrome. Several weeks after the conclusion of the Gulf War, Schwarzkopf returned to MacDill Air Force Base in Tampa to a tumultuous welcome. He writes in his autobiography, "One guy, a Vietnam vet wearing jungle fatigues, a Fu Manchu mustache, and hair halfway down his back, threw his arms around my neck crying. 'Thank you, thank you! You finally made it right'" 
(492). For those people who follow a "dramatistic" approach, the American victory in the Persian Gulf was more than sufficient to symbolically restore the US military to its pre-Vietnam War status.

\section{Equation 5: Return to Vietnam + Admission of Emotions = Renovatio}

In an essay entitled "The Psychology of Rebirth," Jung writes that rebirth is an archetypal process which takes place totally beyond the range of human sense perception. Unlike a physical change in the human body, a psychological rebirth is "a purely psychic reality." A person can communicate their rebirth experience to others only by indirect means, i.e., by personal testimony. Jung writes, "One speaks of rebirth; one professes rebirth; one is filled with rebirth. This we accept as sufficiently real" (Archetypes 116).

Jung enumerated five different ways a person can experience an archetypal rebirth. The form which most closely matches the process exhibited in SVN:ASR is the renovatio, which suggests a magical rejuvenation or revitalization within the normal span of a person's life. One's basic personality is not changed by this process, Jung writes, "but only its functions, or parts of the personality, are subjected to healing, strengthening, or improvement." So powerful is this process, Jung writes, that an individual's physical ailments can be cured through ceremonies of rebirth (Archetypes 114). The "ceremony of rebirth" exhibited in SVN:ASR follows the last formula presented in this study. Schwarzkopf experiences a renovatio by returning to Vietnam and giving voice to things long repressed, to tell others what the Vietnam War did to him psychologically.

Schwarzkopf's return trip to contemporary Vietnam is symbolic of an archetypal journey into the unconscious, where he must confront "all the uncanny things that live in the depths of the psyche" (Jung, Archetypes 12). According to Jung, one of the mysterious archetypal beings lurking in the depths of the human psyche is the shadow. For a person to become aware of his or her shadow, Jung writes, entails "recognizing the dark aspects of the personality as present and real" (Aion 8). The qualities which constitute the shadow are emotional in nature and represent "the existence of a lower level of personality," which can offer a stiff resistance to incorporation into the conscious personality (Jung, Aion 9).

Janice Rushing and Thomas Frentz examined the confrontation with the shadow in their analysis of the film The Deer Hunter. They argued that the film should be viewed as a Vietnam War film; rather, it is a film that depicts war as a male initiation ritual and the psychological changes men undergo by participating in the ritual. In war, the soldier faces his shadow figure. If war is viewed as sacred, then by destroying one's enemy one enters into adulthood, returning to society in triumph. Only the warrior with a strong, well-defined persona will be able to successfully confront the enemy, his shadow, and psychologically survive the war experience. In SVN:ASR, I suggest that Dan Rather embodies the archetypal shadow figure. He questions Schwarzkopf throughout the program, constantly probing and prodding Schwarzkopf to reveal his memories and emotions. The struggle for Schwarzkopf is to maintain his persona of "leader" in the face of this constant barrage of questions, to acknowledge the emotional aspects of his personality without losing the defining qualities of his persona -- authority, command, rationality, and self-control.

During the final segment of SVN:ASR, the television audience witnesses several individuals undergoing a similar process of renovatio. Schwarzkopf and Rather join other Vietnam veterans and listen to their personal accounts of how the Vietnam War affected their lives. One such veteran, Bill Koutrouba, served in Vietnam as a combat medic. He recounts to Schwarzkopf and Rather the frustration he felt as he watched young soldiers die in his arms. "And in the end you just rock them till they died because there was nothing else to do," he says. "And they're always with me. They're always with me." Koutrouba's inner turmoil is apparent as he describes for Schwarzkopf and Rather how he would sit alone at night and play Russian roulette with a .44 Magnum while his family slept. For Koutrouba and other veterans, the only way to exorcize the demons is to return to Vietnam. They return alone or in small groups, looking for familiar faces and sites from long ago. Some of the veterans, both men and women, work through their feelings by participating in small construction projects in Vietnamese villages. As a former Red Cross volunteer tells Schwarzkopf and Rather, "Vietnam will never be done for me, but the bad feelings toward the Vietnamese are done and that was a really critical thing I had to get over."

As the SVN:ASR reaches its closing minutes, Schwarzkopf has undergone a visible change. He no longer exhibits any anxiety about returning to Vietnam. His outward calmness corresponds to an inner tranquility. When asked by Rather to sum up his emotional state, his overall feelings about his return trip to Vietnam, Schwarzkopf replies, "I guess the bottom line for me, not for anybody else, but the bottom line for Norm 
Schwarzkopf is the war is over. The war is over, and it really wasn't over until I came here." Schwarzkopf's return to Vietnam coupled with his admission of emotions has led to his renovatio, a rebirth. The persona of General H. Norman Schwarzkopf carried with it a classic case of survivor's guilt; he completed his two combat tours in Vietnam and returned home while some of his West Point classmates, his officers, and his enlisted troops died. After undergoing the archetypal rebirth experience, he has been transformed into Citizen Schwarzkopf. Citizen Schwarzkopf recognizes that he will carry his Vietnam experiences with him throughout his natural life, but these experiences no longer dominate his psyche.

In The Philosophy of Literary Form, Burke posits, "Are not wars what we make of them - like stones and trees, like Napoleon and the history of Greece?"(238). Americans have been struggling with what to make of the Vietnam War from the beginning. In SVN:ASR, Schwarzkopf shows how to make that war a memory.

\section{Works Cited}

- Burke, Kenneth. The Philosophy of Literary Form: Studies in Symbolic Action. Berkeley: U of California Press, 1941/1973.

. A Grammar of Motives. Berkeley: U of California Press, 1962.

. Language as Symbolic Action. Berkeley: U of California Press, 1966.

- Jamieson, Kathleen Hall. Eloquence in an Electronic Age: The Transforming of Political Speechmaking. New York: Oxford UP, 1988.

- Jung, Carl Gustav. The Archetypes and the Collective Unconscious. Princeton: Bollingen Series XX/Princeton UP, 1959.

- Aion: Researches into the phenomenology of the self. Princeton: Bollingen Series XX/Princeton UP, 1959.

- Larson, Charles U. Persuasion: Reception and Responsibility. Belmont: Wadsworth, 1995.

- Ling, David A. "A Pentadic Analysis of Senator Edward Kennedy's Address to the People of Massachusetts, July 25, 1969." Rhetorical Criticism: Exploration and Practice. Ed. Sonja K. Foss. Prospect Heights: Waveland, 1989. 344-351.

- Schwarzkopf in Vietnam: A Soldier Returns. CBS. 30 June 1993.

- Olson, Kathryn M. "The Controversy over President Reagan's Visit to Bitburg: Strategies of Definition and Redefinition." The Quarterly Journal of Speech, 75 (1989): 129-151.

- Rushing, Janice. Hocker and Frentz, Thomas S. "'The Deer Hunter': Rhetoric of the Warrior." Quarterly Journal of Speech, 66 (1980): 392-406.

- Schwarzkopf, H. Norman and Petre, Peter. It Doesn't Take a Hero. New York: Bantam, 1992.

- Sutton, David. "The Fullest Possible Accounting: The Myth of American POW/MIAs in Southeast Asia, 1973 to 1993." Committee's Choice: Top Three Papers in American Studies. Speech Communication Association convention. Marriot Rivercenter, San Antonio. 19 November 1995.

\section{Author Information}

David SUTTON received his Ph.D. in Speech and Communication from the University of Georgia. At present, he is an Associate Professor at the Department of Communication, Auburn University, Alabama. 